\title{
A SEXUALIDADE E AS RELAÇÕES DE GÊNERO NA CONSTRUÇÃO DA AFETIVIDADE DAS MULHERES LÉSBICAS
}

\author{
THE SEXUALITY AND GENDER RELATIONS IN THE CONSTRUCTION OF LESBIAN \\ WOMEN'S AFFECTIVITY
}

\author{
Aparecido Francisco dos Reis ${ }^{2}$ \\ Fernanda Chaves Campos ${ }^{3}$
}

\begin{abstract}
RESUMO: O objetivo deste trabalho é analisar a trajetória de vida das interlocutoras, a fim de investigar acerca da sexualidade dessas mulheres, apoiando-se em percepções de questões de gênero e seus papéis tradicionais definidos por meio da heteronormatividade. A presente pesquisa foi elaborada através de revisão bibliográfica e entrevistas em profundidade. A amostra selecionada, por sua vez, é composta por cinco mulheres lésbicas que, em sua maioria, não performam feminilidade. Empregada de maneira pejorativa, percebe-se que a palavra "lésbica" e seus derivados aparecem, primeiramente, durante a infância das interlocutoras, sempre associada a comportamentos considerados "masculinos". Isto é, neste primeiro momento, nota-se que ser lésbica diz mais sobre o que você veste e do que/com quem você brinca, do que sobre sua sexualidade. Já durante a adolescência, os resultados indicam que diferentes contextos sociais possibilitam diferentes processos de autoafirmação e aceitação, como no caso das interlocutoras oriundas de famílias religiosas, que encontraram maior dificuldade em se aceitar como mulheres lésbicas, muitas vezes cedendo à pressão familiar e recorrendo à heteronormatividade compulsória. Posteriormente, conclui-se que a lésbica que não performa feminilidade é importante para a desconstrução do binarismo de gênero, pois esta não deve ser vista como uma cópia do homem heterossexual, mas uma ressignificação das expressões de gênero.
\end{abstract}

Palavras- chave: heteronormatividade, sapatão, butch

ABSTRACT: The aim of this work is to analyze the interlocutors' life path, in order to investigate about these women's sexuality, supporting itself on gender issues and its traditional roles defined by means of heteronormativity. The present research was developed by literature review and in-depths interviews. On the other hand, the sample selected is composed of five lesbian women, who, in the majority, don't perform femininity. It can be noticed that the "lesbian" word and their derivatives, utilized in a pejorative manner, firstly appear during the interlocutors' childhood, always related to behaviors considered "masculine". In other words, at this first moment, it can be noticed that being a lesbian says

\footnotetext{
${ }^{\mathrm{I}}$ Este artigo é parte do projeto de pesquisa "A erótica dissidente: A afetividade e a sexualidade de mulheres e homens LGBTs", com financiamento parcial do CNPQ e Bolsa de Iniciação Científica da UFMS no período 2019-2020

${ }^{2}$ Professor da UFMS, Departamento da Faculdade de Ciências Humanas; e-mail: aparecido.reis@ufms.br.

${ }^{3}$ Aluna do Curso de Ciências Sociais da UFMS, bolsista de Iniciação Científica UFMS - PIBIC 2002/o3; email: fechaca@gmail.com.
} 
more about what you dress or what/whom you play with, than your sexuality. During adolescence the results indicate that different social contexts enable different self-affirmation and acception processes, as in the intercolutors' cases from religious families, who found more difficulty in accepting themselves as lesbian women, oftentimes giving in to family pressure and resorting to compulsory heternormativity. Afterwards, it concludes that the lesbian who doesn't perform femininity is important for the gender binarism deconstruction, since she shouldn't be seen as a copy of the heterosexual man, but a new meaning of gender expression.

Key words: heteronormativity, dyke, butch

\section{INTRODUÇÃO}

Este texto foi produzido a quatro mãos numa parceria entre orientador e aluna do Programa de Iniciação Científica da Universidade Federal de Mato Grosso do Sul, como parte do projeto de pesquisa acerca da afetividade e sexualidade de pessoas Lésbicas, gays, bissexuais, transexuais, queers, interssexuais e assexuais (LGBTQIA+). A pesquisa sobre a temática começou a ser organizada no ano 2015. No primeiro momento, buscou-se levantar dados sobre a afetividade de transexuais, travestis e homens gays, sendo que boa parte desses dados já foram publicados (Reis, Silva, 2020; Reis, 2019)

Deste processo de levantamento de dados participaram alunos gays, um aluno que era Garoto de Programa e uma mulher trans, propiciando aos mesmos a experiência do trabalho acadêmico, a proximidade e o distanciamento do campo de pesquisa, assim como a interlocução entre a universidade e os sujeitos sociais em questão. Tem sido um processo enriquecedor o diálogo entre academia e pessoas LGBTQIA+, mantido através de pesquisas e da participação de líderes do movimento em eventos científicos no campus universitário, expondo suas inquietações e demandas. A interlocução criada e mantida a aproximadamente 20 anos tem sido um facilitador nas aproximações entre as (os) pesquisadoras (es) com o campo de estudo, possibilitando um trânsito livre entre os sujeitos de pesquisa, ao mesmo tempo que coloca pessoas LGBTQIA+ nas reuniões de estudos, cursos, programas de prevenção e conscientização dentro da universidade. Dessas parcerias ao longo dos anos resultaram diversos projetos de pesquisa e extensão, nos quais, não sem as dificuldades inerentes, tem sido um ponto forte que tem propiciado um ambiente aberto para a produção acadêmica de participantes gays, lésbicas e transexuais no grupo de pesquisa sobre violência, 
gênero e sexualidade da UFMS e nos projetos de iniciação científica (Reis; Silva, 2020; Gomes, Kurashige, Reis, 2013; Carvalho, Reis, 2016).

No caso específico da pesquisa com as mulheres lésbicas, houve a participação de uma acadêmica manifestadamente lésbica mediando o processo de aproximação, a coleta de dados por meio dos relatos e análise do material sob a supervisão do orientador.

Ao longo dos anos do curso de Ciências Sociais, com o auxílio da Antropologia e dos estudos de gênero, enquanto mulher lésbica passei a entender o porquê da ausência de mulheres no corpo docente do curso, embora haja vários professores gays. Até certo ponto, eu ainda não havia questionado o porquê da ausência de mulheres lésbicas neste meio acadêmico, predominantemente heteressexual e masculino. Portanto, enquanto mulher lésbica e estudante de graduação, eu passei a entender a urgência de se ocupar lugares, reivindicar espaços e produzir sobre a lesbianidade na Academia. Assim sendo, esta pesquisa é resultado dessa necessidade de se escrever sobre a trajetória de mulheres lésbicas, sobre seus amores e desamores, principalmente em um contexto sul-mato-grossense - um estado demasiadamente machista -, pois, onde há mulheres, também há séculos de história que as apagam da ação no mundo (SWAIN, 2000, p. 22), logo, entende-se que a mulher lésbica é apagada duas vezes. Primeiro por ser mulher, e em segundo, por desinteressar-se sexualmente por homens, negando, assim, seu papel social de esposa heterossexual e mãe uma verdadeira "fraude" contra a procriação (FOUCAULT, I988).

Destarte, o presente trabalho aborda fragmentos dos relatos de mulheres lésbicas, desde a infância até o momento atual, a fim de investigar como certas construções e percepções heteronormativas estão presentes - e até certo ponto, ausentes - tanto na história de vida, quanto nos relacionamentos amorosos da amostra entrevistada. Os apelidos de infância, os preconceitos sofridos e os estereótipos reproduzidos são elementos presentes nos depoimentos das interlocutoras e cruciais para uma problematização em termos de relações de gênero.

Aqui, se entende gênero a partir de duas definições fundamentais de Joan Scott (1995), isto é, como um "elemento constitutivo de relações sociais baseadas nas diferenças percebidas entre os sexos" e "uma forma primária de dar significado às relações de poder". Destarte, através de uma 
análise interpretativa dos depoimentos aqui levantados e da bibliografia referenciada, buscase averiguar como tais relações desiguais de poder, oriundas das relações de gênero, afetam as vidas e relacionamentos de mulheres lésbicas. $O$ conceito de poder empregado anteriormente aproxima-se do poder foucaultiano, ou seja, não é unificado, nem centralizado, mas "entendido como constelações dispersas de relações desiguais, discursivamente constituídas em "campos de força" sociais" (SCOTT, 1995, p. 86).

De acordo com Michel Foucault (1988), no século XIX a sexualidade passou a ser usada como um dispositivo para normalizar, regular e produzir "verdades" sobre o sexo e o corpo dentro de uma visão heteronormativa - marcada por um moralismo burguês e cristão -, onde a homossexualidade representava a decadência da família e da moral. Para o autor, a sexualidade aparece tanto como uma forma de poder como forma de estar sujeita a poderes. Este trabalho foi desenvolvido em Campo Grande, Mato Grosso do Sul, através de revisão bibliográfica e entrevistas em profundidade. Plataformas online como o Google Acadêmico, SciELO e Periódicos CAPES - assim como revistas acadêmicas - possibilitaram uma busca, no geral, satisfatória sobre a temática, mas limitada na área de Ciências Sociais. As palavraschave utilizadas nas buscas foram: lesbianidade, lesbianismo, lésbicas, sapatão. Após a leitura exploratória e seletiva, a pesquisa foi divulgada na rede social Twitter ${ }^{4}$, alcançando mais de 50 retweets, isto é, compartilhamentos. Embora algumas pessoas tenham marcado e indicado outras, deu-se prioridade para as mulheres com as quais já havia ocorrido algum tipo de contato anterior, como seguidoras mútuas, a fim de facilitar o conforto entre pesquisadora e entrevistadas durante o processo.

Após a divulgação, decidiu-se qual seria a amostra pesquisada: cinco mulheres de 20 a 25 anos que se consideram lésbicas e residem em Mato Grosso do Sul. Mulheres cis brancas, negras, gordas e magras que após concordarem em participar da pesquisa, leram e assinaram o termo de consentimento livre e esclarecido (TCLE), permitindo a gravação das entrevistas e garantindo o sigilo de suas identidades. Seus nomes fictícios, inclusive, foram escolhidos aleatoriamente.

4 Twitter é uma rede sociale um servidor para microblogging, que permite aos usuários enviar e receber atualizações pessoais de outros usuários, através de textos de até 280 caracteres, conhecidos como "tweets". (Fonte: Wikipedia) 
Inicialmente, o trabalho de campo - o "estar lá”, de Geertz (1998) - aconteceria em encontros individuais com as entrevistadas, inclusive em locais que elas frequentam, contudo, devido ao avanço da pandemia da COVID-ı9, apenas uma entrevista ocorreu pessoalmente, enquanto as outras foram realizadas no âmbito virtual. Assim, as entrevistas em profundidade foram realizadas através do aplicativo de celular, Whatsapp, onde, primeiramente, pediu-se para as interlocutoras iniciarem contando suas histórias de vida começando por onde, quando e com quem cresceram, passando pela infância, adolescência, até os dias atuais. Já que as entrevistas em profundidade são “menos estruturadas e podem abranger apenas um ou dois aspectos, mas com muito maior detalhamento" (BRITTEN, 2009, p.24), outras perguntas e comentários foram feitos pela pesquisadora apenas quando algo de interesse do estudo não havia sido explorado.

A discussão da bibliografia sobre o tema pesquisado será realizada no diálogo com as falas das entrevistadas, isso pareceu mais adequado para o enriquecimento da compreensão das narrativas apresentadas.

\section{RESULTADOS E DISCUSSÃO}

Antes de iniciar a discussão sobre a trajetória de vida das interlocutoras, entende-se que introduzi-las para os leitores é primordial, mas tal introdução será feita de maneira breve, para que o sigilo sobre a identidade dessas mulheres entrevistadas não se comprometa. Por sua vez, Antonella, hoje aos 23 anos, cresceu no interior de Minas Gerais e após se formar em História, veio para o Mato Grosso do Sul. Pietá, de 25 anos, é formada em Psicologia e, atualmente, faz mestrado na capital do MS. Juno, de 2I, cresceu em Goiás e veio para Campo Grande cursar Jornalismo. Helena, aos 25, além de ser formada em Administração pela UFMS, é militante do movimento feminista e do movimento de mulheres lésbicas, atualmente reside em Bonito. Ana, também aos 25, cresceu em Campo Grande e é a única interlocutora fora do meio acadêmico.

\section{Eu sempre fui uma criança viada}


A infância contém relatos importantes, visto que "a socialização das crianças é um processo de formação de pequenas fêmeas e machos ensinados, desde o berço, que cada sexo tem seu lugar e seus limites, suas preferências corretas, seu caminho definido" (SWAIN, 2000, p.62).

"A gente sempre teve um jeito diferente das demais meninas, 'né'. Do que é dito como ser menina, do que é dito como é ser mulher. Do que é dito como... do que é construído pela sociedade como uma menina deve se portar. Principalmente assim nos primórdios da nossa infância. E eu sempre me desvirtuei destes pré-conceitos estabelecidos, 'né'." (Antonella, 23 anos)

As problematizações levantadas por Antonella são comuns em contextos acadêmicos, pois além de sua formação em História, a interlocutora alegou já ter participado de debates sobre gênero e leituras antropológicas - o que explica o nível (politizado) de seu discurso. Retomando Tânia Navarro Swain (200o), “o preço da normalidade é a domesticação, a disciplina do múltiplo humano em torno da crença do binário" (p.62), assim, as crianças têm seus corpos regulados e domesticados, cuidadosamente educados para exercerem seus devidos papéis sociais de futuros homens e mulheres e, nesta lógica binária, nem as brincadeiras escapam:

“Tinha a questão da menina que não gosta de brincar de boneca, a menina que não gosta de ficar em casa. Eu sempre fugi mais desse parâmetro e cai na menina brincalhona, a menina que gostava de ficar na rua soltando pipa, que fazia pipa, que usava boné pra trás, que corria com as meninas, que corria descalço.” (Antonella, 23 anos).

\section{Pietá acrescenta}

"Na época do colégio assim, eu costumo dizer pra minha noiva que eu sempre fui uma criança viada, no sentido de que eu fui essa criança caminhoneira, sempre gostei muito de futebol, de coisas que envolviam ação ou as brincadeiras que eram de meninos, como se costuma dizer. E eu sempre sofri muito bullying por isso também, de virem me chamar de lésbica como se fosse uma ofensa." (Pietá, 25 anos)

A criança viada, descrita por Pietá e objeto de análise em estudos queer, é a criança que rompe com as normas heteronormativas de expressão de gênero, isto é, são corpos infantis que resistem "aos diferentes mecanismos de poder, rebelam-se, contestam e bagunçam as normas que os querem produzir e governar" (PARAÍSO; SILVA, 2017, p.I). A menina que brinca na rua com os meninos, que joga bola, solta pipa e não gosta de rosa. $\mathrm{O}$ menino que não joga bola, brinca de boneca e se veste com roupas da mãe quando ninguém vê. São todos crianças viadas.

"Eu vivia no meio dos meninos, por causa dos brinquedos e, sei lá, acho que preferência também, porque eu não era de brincar de boneca, eu não era de brincar de Barbie, essas coisas... Meus brinquedos eram todos de, sei lá, esporte, sabe? Era tipo patinete, patins, skate, esse tipo de coisa.” (Juno, 2I anos) 
Logo, entende-se brincadeiras de meninos como aquelas em que se brinca na rua, correndo e jogando. As brincadeiras de meninas, por sua vez, são em casa, reproduzindo as funções domésticas e a maternidade (SOARES, 2016, p. 173). Outro fator importante e recorrente na infância dessas mulheres é a problemática - muitas vezes imposta pela família - de suas vestimentas consideradas masculinas. Ou seja, quando se é menina, o guarda-roupa ideal é composto por vestidos, saias e blusas com recortes femininos, justos e cor-de-rosa. Camisetas largas, camisas de botão e acessórios como boné, são tidos como “coisas de menino". Constatações como essas, implicam em acontecimentos como esse:

"Sabe aquelas sandálias do Senninha? Era uma sandália que era tida como masculina, mas eu e minhas amigas a gente usava. Eu lembro de mudar de colégio e quando eu fui no banheiro feminino com uma "sandalinha" daquela assim, eu lembro das meninas acharem que era um menino que tava dentro do banheiro. E tudo aquilo que era relacionado de vestimenta que não era muito de menina, no sentido que eles pregam que era coisas rosas, saia, enfim, eu nunca me enquadrei nesse tipo de vestuário. E eu lembro de ser taxada como menininho e até falarem que eu gostava de meninas por conta disso e assim, não tinha nada a ver na época, eu ainda nem tinha começado a ficar com menina, nem nada disso, ainda nem tinha iniciado minha vida sexual, amorosa. E eu lembro de já taxarem as meninas que não se vestiam dessa forma como sapatão, sabe? E na verdade era só uma vestimenta mais confortável pra gente brincar, se divertir, subir na árvore brincar no pátio, jogar bola, andar de bicicleta." (Helena, 25 anos)

Ainda sobre vestimenta, Ana acrescenta

"Sempre fui machinho, minhas fotos de criança sempre foi de xadrezinho, de capuz, de boné, na bicicleta, sempre fui arteira... tenho esse... eu acho até que esse meu papel de 'arteira' veio um pouco de ser mais 'molecona', eles falam mais 'gurizona', 'né'. Ah, tem vários estereótipos que a gente acaba levando." (Ana, 25 anos)

Este fragmento da entrevista de Ana demonstra a consciência que ela, assim como outras mulheres lésbicas, tem da existência de estereótipos construídos e perpetuados social e culturalmente a partir de sua expressão de gênero. De acordo com Andrea Lacombe (2010), Os significados de se ser mulher estão atrelados a determinadas pautas sociais e morais que sinonimizam mulher com feminino, homem com masculino e inserem ambos no interior de um padrão heterossexual. As noções de feminino e masculino, por sua vez, estão estereotipicamente associadas a diversas características que costuram os significados do que se considera um comportamento "próprio" de cada uma delas. (LACOMBE, 2010, p. 174)

Conforme Gilberta Soares (2016) explica, "as vestimentas tomam parte da vida dessas mulheres $e$ de seus discursos de forma muito significativa. Ao vestir roupas masculinas, elas compõem o masculino, performatizando um gênero que transgride as normas pré-estabelecidas." (p.175). Assim sendo, a mulher que não expressa os códigos adequados do feminino - como a feminilidade 
- é imediatamente associada a uma figura "confusa", familiarizada à pergunta "você é homem ou mulher?” desde a infância.

"Eu era rodeada de moleque, porque eu comecei a andar de skate e me vestia igual menino mesmo, com roupa muito larga. E aí eu ouvia muito das crianças assim “ah, você é um homem ou uma mulher?”esse tipo de coisa, e sei lá, pra mim era tanto faz, sabe? Eu não ligava muito pra isso, só tava confortável com a roupa que eu vestia e o estilo também." (Juno, 2r anos)

\section{Eu já sabia}

Segundo Andrea Lacombe (2010), a autenticidade da lesbianidade está ligada "à noção de natural, não como resignação de "não se poder ser outra coisa", como justificativa de um lugar de fraqueza, mas, ao contrário, como legitimação e valor (p.5I). Com isso, Ana relata, "eu me afirmei na minha sexualidade antes de beijar a primeira mulher, eu contei pra minha mãe que eu era lésbica antes de beijar minha primeira mulher, porque eu já sabia." Observa-se que esse sentimento de "já saber” se encontra no discurso de mais três interlocutoras:

"Acho que não vou me dizer enquanto descoberta, porque na verdade eu acho que não descobri nada. Sabe, tipo assim, eu não parei num momento e descobri “nossa, eu sou lésbica. Nossa, eu sou 'sapatão". Acho que não chegou a ser uma descoberta, mas, sim, eu vou colocar enquanto uma aceitação, que acho que comigo o que aconteceu foi uma aceitação.” (Antonella, 23 anos)

Compartilhando do raciocínio de Antonella, Juno afirma "eu acho que tudo começou na minha infância, sabe? Porque eu não acredito que isso, tipo assim, a gente se descobre, eu acho que a gente sempre sabe e aí a gente vai aceitando aos poucos.” Já Helena, por sua vez, “ $\mathrm{Na}$ adolescência eu já sabia que gostava de mulheres, então, assim, de alguma forma ali na infância, na adolescência eu já tinha essa consciência que eu gostava de mulheres. Eu acredito que o principal marco foi quando eu entrei na universidade quando eu tinha 17 pra 18 anos e a partir dali eu fui conhecendo pessoas novas, pessoas de outros cursos, fui entrando em debates diferentes sobre sexualidade, sobre corpo, sobre mulheres, dentro do movimento estudantil também é algo que sempre tem também, né, os questionamentos, tem palestras... E eu acho que a partir dali eu comecei a entender e me ver de fato como alguém comum, não era algo anormal gostar de mulher." (Helena, 25 anos)

Assim como no caso de Antonella, a experiência acadêmica de Helena também a ajudou no que diz respeito à auto-aceitação e construção de uma compreensão mais ampla sobre si mesma:

"Até então me considerava bissexual, né. Então depois que eu conheci mais o debate e que eu também comecei a me relacionar de fato com mulheres assim, não só ficar com mulheres, não só beijar na boca de mulheres, mas me relacionar de fato com mulheres eu fui entendendo que a bissexualidade não cabia e que eu não queria mesmo ficar com homens, eu queria realmente namorar com mulheres, enfim." (Helena, 25 anos) 
Embora os três discursos se aproximem, Antonella e Juno passaram por experiências que não foram relatadas por outras interlocutoras: a regulação moral e sexual do cristianismo. Conforme Tânia Navarro Swain (200o), no Ocidente, o cristianismo criou em torno da sexualidade um nimbo de pecado, fazendo da "reprodução, esta função física, o eixo em torno do qual passou a girar a vida social, material, espiritual estruturada na família heterossexual e na instituição do casamento monogâmico" (p.54).

"Durante todo esse tempo aí dos 17 até meus 18 eu ainda estive muito presente na igreja, o que dificultou me aceitar, me dificultou falar sobre, me dificultou ter relações, me dificultou por várias coisas, sabe? E eu sempre ia em retiro espirituais, retiro de igreja, e conversava com padre, e pedia pro padre pra me ajudar, pedia pro padre me perdoar, falava que Deus não ia me aceitar e que por isso eu ia ser julgada. Enfim, foi um trabalho muito mais difícil quando eu estava na igreja, 'né'. Muito mais difícil, muito mais doloroso, porque lá 'cê' não podia ser, a gente ia nos retiros de jovem, sabe? De igreja assim, e sempre tinha alguma palestra que falava sobre sexualidade e sempre colocava as pessoas que, 'sei lá', praticavam algum ato sexual ou alguma coisa do tipo como uma pessoa que era desviada, uma pessoa suja, uma pessoa que não podia estar ali naquele meio e isso pesava muito na minha cabeça e me levava sempre a querer voltar atrás". (Antonella, 23 anos)

Apesar das transformações culturais e sociais que se passaram desde o século XVIII, a Igreja e a família ainda se mostram as principais instituições de regulação e normalização - de sexualidades errantes e improdutivas (FOUCAULT, 1988) - aqui citadas. Entretanto, entre os cinco depoimentos utilizados nesta parte da análise, o que mais se difere dos outros é o de Pietá, visto que,

“Eu fui me entender lésbica deve ter... não sei, dois anos no máximo (...) quando eu entrei na faculdade eu já namorava um menino, eu namorei com ele por cinco anos, então eu fui terminar o meu namoro com 22 anos. Enquanto eu tava com ele foi tranquilo, assim, a minha relação com ele... Até aquele momento eu não questionava se eu gostava de homem ou não, pra mim era muito tranquilo, eu não tive nenhuma restrição quanto à relação de sexo ou de nada do tipo, mas aí depois de um tempo eu fui entendendo, até junto com ele, que 'tipo', eu tinha curiosidade de ficar com menina, porque eu não sabia se eu poderia gostar ou não, eu nunca tinha beijado nenhuma menina até então." (Pietá, 25 anos)

Enquanto as outras interlocutoras disseram saber desde a infância que gostam de mulheres,

Pietá descobriu somente após seus 20 anos e, por ser mais velha e encontrar-se em outro contexto, seu processo de auto-aceitação foi demasiadamente diferente das outras:

“Quando eu me dei conta de que eu gostava de mulher, eu 'tava' em terapia, eu estou em terapia, inclusive, até hoje, então foi uma coisa que eu tive apoio de processar, assim... que eu acho que não teria se eu tivesse que ter feito isso na adolescência. Então foi muito tranquilo assim, tranquilo no sentido pessoal de "ah, ok, fiquei com menina, gostei, tudo bem, eu não me sinto mal, não me reprimo por isso, nem nada do tipo" e levei numa boa minha sexualidade assim." (Pietá, 25 anos) 
Ademais, a trajetória de mulheres lésbicas é constantemente marcada - e apagada - pela heterossexualidade compulsória, ou seja, a normalização e imposição da heterossexualidade como sexual e emocionalmente natural às mulheres ( $\mathrm{RICH}, 2012)$. Antonella, por exemplo, relata como já sabia que gostava de mulheres e mesmo assim continuou a se relacionar com homens para agradar à família.

“Eu perdi o 'B.V's na escola lá na, sei lá, oitava série. E sempre aquela pressão, 'né'? "Você tem que perder o 'B.V'. com um menino, não pode ser uma menina”, aí na minha cabeça eu nem cogitava mais ser uma menina, apesar de que, me recordo de vários momentos em que eu sempre olhava pras meninas e ficava "mas eu não posso" (...) e eu segui minha vida por muito tempo ficando com garotos, acho que até meus I4 anos eu ficava com meninos, né. Normal, assim, teoricamente. Eu me sentia em várias vezes me mutilando, uma sensação assim de "não quero fazer isso", mas aí pela vibe você acaba fazendo e tal.” (Antonella, 23 anos)

A heterossexualidade compulsória pode ser definida como "um mecanismo regulador de práticas e definidor de papéis, restritos aos desenhos morfológicos e genitais, isto é, à correspondência exata entre sexo biológico/gênero social” (SWAIN, 2000, p.77). Apesar das mulheres estarem expostas à heterossexualidade compulsória de uma maneira geral, não foram todas que relataram experiências heterossexuais em suas trajetórias. A Ana, inclusive, introduz o termo "lésbica golden star" em seu depoimento, que se resume a "nunca ter dito intercursos sexuais com homens" ou "de não ter no currículo uma história de conjugalidade heterossexual" (LACOMBE, 2010, p. 151).

Neste momento da entrevista, perguntei à Ana se ela havia ouvido muito a pergunta “como você sabe que é lésbica se nunca transou com um homem?”, e ela respondeu, "não, porque eu sempre fui mais machinho (...) quando você se comporta mais machinho os caras parecem te respeitar mais do que quando você é mais feminina." Aqui, entende-se o "se comportar mais machinho" como uma prática parodística, assim como a lésbica butch (BUTLER, 2003), retomada no próximo capítulo.

\section{Ela me deu uma cotovelada na costela e falou no meu ouvido: lésbica}

5 "B.V." é a abreviação de "boca virgem", usado por jovens brasileiros para se referir ao primeiro beijo. 
Ao estudar a polissemia da palavra "lésbica", Tânia Navarro-Swain (200o) relata que, "houve um tempo que lésbica era a mulher nascida em Lesbos, ilha grega na Ásia Menor, marcada pela presença de Safo, poetisa de talento excepcional cuja inspiração era insuflada pela paixão e desejo pelas mulheres" (p.29). Isto posto, no século XX,

(...) os dicionários atrelam à ilha de Lesbos, onde Safo vivia, as definições de lesbianismo: práticas sexuais, mas igualmente sentimentos e emoções. De acordo com o Koogan Larousse (1979: 507): "Lésbico: diz-se do amor sexual de uma mulher a outra". Na Enciclopédia Encarta 1999, em CD-ROM: "Lésbica: mulher homossexual, mulher-homem, mulher-macho. Chulo: sapatão". Quanto ao adjetivo: "Lésbico: diz-se do amor de uma mulher a outra". (Ibidem, p.33-34)

A definição da Enciclopédia Encarta (1999), coincide inteiramente com os apelidos dados às interlocutoras durante a infância. Mulher-homem, sapatão, Maria-macho e lésbica são categorias presentes na maioria das entrevistas, primeiramente, de forma pejorativa:

"Maria-macho, Maria João, sapatão. Nossa... acho que isso era o que mais me incomodava, sabe? Tanto que, na infância, se a pessoa falasse "Ah, Maria-macho...” Maria-macho naquela época me incomodava, porque eu me sentia como uma pessoa que... sei lá, é como se tivessem se desfazendo de mim, sabe? Eu era uma pessoa que causava vergonha, que causava repulsa porque eu era Maria macho, eu era tipo assim, eu não era nem um, nem outro." (Antonella, 23 anos,)

Por sua vez, Ana,

“A gente [ela e sua irmã] discutiu e aí a gente se cruzou numa parte da casa, assim, entre os quartos, daí no que ela me cruzou, ela me deu uma cotovelada na costela e falou no meu ouvido: lésbica. Nossa, aquilo me atingiu de um jeito... eu tratei depois, fiz terapia um tempo depois, eu comentei isso, minha mãe foi chamada lá e a gente comentou disso tipo." (Ana, 25 anos)

Entre as palavras mulher-homem, Maria João, Maria-macho e sapatão, citados anteriormente, "sapatão" é a única que foi apropriada e ressignificada por mulheres lésbicas - dentro do recorte geracional das entrevistadas -, assim como o termo queer em i98o, pela comunidade LGBTQ+ (LACOMBE, 2010).

"Eu sempre brinco com as meninas que a gente tem mania de se cumprimentar "e ai, sapatão! Ô sapatão e tal" e a gente se chama de sapatão o tempo inteiro, que a gente ressignificou a palavra "sapatão", sabe? Que era uma palavra que machucava tanto e feria tanto, ouvir era, pelo menos pra mim, ouvir a palavra sapatão, alguém te chamando de sapatão, "Ô SAPATÃO", sabe? Era como se ela tivesse me colocado numa camada extremamente pejorativa, me colocava como uma pessoa completamente imoral, sabe? Há um tempo atrás, há alguns anos atrás, sapatão era uma palavra que machucava. Pra mim hoje é um elogio. Sabe, uma amiga minha me gritar "e aí, sapatão" eu “ô sapatão, beleza, 'véi'?” tipo assim, pra gente virou uma forma de se auto-afirmar, sabe? É uma palavra de afirmação, e não é uma afirmação mais da vergonha, sabe?” (Antonella, 23 anos,)

\section{Tudo bem beijar meninas, mas não vai se vestir igual homem}


Para Tânia Navarro Swain (2000), existe, no imaginário social, uma tipologia da mulher lésbica. Aqui, focamos na tipologia mais característica que, nas palavras da autora, é a "mulher-macho, paraíba, sapata, fanchona, caminhoneira, butch, dyke, identificada por um mimetismo das atitudes e maneiras masculinas" (p.8o). Ademais, a autora acrescenta,

É possível que a rigidez da divisão binária da sexualidade humana faça com que a atração por outras mulheres crie a necessidade de adotar as características masculinas, físicas e comportamentais, tosca forma de encenar a sedução (Barret, 1990: 257). Dessa forma, as mulheres em geral, "femininas", poderiam sentir-se atraídas por esses tipos masculinizados. Temos aí o esquema da ordem heterossexual em corpos biologicamente femininos, o casal butch/femme. (Ibidem)

De acordo com Mariana Ferreira Pombo (2017), "butch é o nome que se atribui à lésbica "ativa", identificada com a masculinidade, enquanto femme seria a lésbica "passiva”, mais feminina" (p.394). Seguindo a lógica proposta por Swain (200o) e por Pombo (2017), observemos o depoimento de Antonella sobre seu primeiro relacionamento com uma menina, aos 16/17 anos:

“(...) tinha várias coisas que ela me obrigava a fazer porque ela não aceitava que, por exemplo, ela namorasse com uma menina que não parecesse uma menina. Ela tinha na cabeça dela que os papeis de gênero deveriam ser um homem e uma mulher, são duas mulheres, mas a performance era um homem e uma mulher. Então ela me cobrava várias coisas como me arrumar, ela me cobrava fazer unha, ela me cobrava até na questão do sexo mesmo, a relação sexual era mais de uma ativa e de uma passiva, porque eu tinha que ser a mais feminina, a mais sensível, e ela fazia o papel mais bruto da relação, sabe?” (Antonella, 23 anos)

Neste relacionamento, Antonella representaria a lésbica femme; sua namorada, a butch. O casal butch/femme também aparece nas análises de Butler (2003), entretanto, na visão butleriana, a noção de que o casal butch/femme seria, em alguma medida, réplica do casal heterossexual é equivocada (p.178), pois

A "presença" das assim chamadas convenções heterossexuais nos contextos homossexuais, bem como a proliferação de discursos especificamente gays da diferença sexual, como no caso de "butch" e "femme" como identidades históricas de estilo sexual, não pode ser explicada como a representação quimérica de identidades originalmente heterossexuais. E tampouco elas podem ser compreendidas como a insistência perniciosa de construtos heterossexistas na sexualidade e na identidade gay. A repetição de construtos heterossexuais nas culturas sexuais gay e hétero bem pode representar o lugar inevitável da desnaturalização e mobilização, das categorias de gênero. A replicação de construtos heteronormativos em estruturas não heterossexuais salienta o status cabalmente construído do assim chamado heterossexual original. (BUTLER, 2003, p.56-57)

Butler (2003) busca demonstrar que a masculinidade manifestada na identidade da lésbica butch pouco tem a ver com uma assimilação oriunda da heterossexualidade, trata-se de uma recontextualização e ressignificação da masculinidade. Portanto, entende-se que a existência "de uma masculinidade de mulheres implica previamente desconsiderar a masculinidade como 
incindível da estrutura biológica do homem e desenhá-la como uma ficção que se constrói performática e socialmente" (LACOMBE, 2007). Infelizmente, ainda há muito que se caminhar para se chegar à plenitude das teorias de Lacombe (2007) e Butler (2003) aplicadas na prática.

“Hoje eu já não tenho problema com roupa, já não tenho problema com a forma de me portar, já não tenho problema com meu cabelo, sabe? Tanto que cortei o cabelo, não tenho mais problema como tinha antes, que eu tinha a necessidade de não parecer muito homem, eu ficava "não, meu Deus do céu, as pessoas vão achar horrível uma sapatão que parece homem, uma sapatão muito masculina, olha que feio" na minha cabeça eu tinha isso, hoje eu não tenho mais essa preocupação, sabe?” (Antonella, 23 anos)

Essa preocupação em não se parecer com um homem, também está presente no depoimento de Juno,

"Eu tinha em mente que pra eu me apaixonar por uma menina, pra pessoa se apaixonar por mim, eu tinha que me vestir mais feminina, sabe? Representar mais feminilidade, e aí eu começava a tipo a pintar unha, a usar salto, a usar roupa mais colada, a soltar o cabelo, a usar batom, lápis de olho, esse tipo de coisa. E aí tipo a maioria dos encontros que eu ia com essa menina eu me vestia assim, porque na minha cabeça ela só ia gostar de mim e eu poderia me relacionar com ela se eu fosse mais feminina, porque eu achava muito errado isso aí tipo assim, tudo bem beijar meninas, mas você não pode ser masculina, sabe? Na minha cabeça era isso, tudo bem beijar meninas, mas não vai se vestir igual homem.” (Juno, 21 anos)

Enquanto Antonella demonstra ter abandonado algumas percepções do passado, Juno reitera,

"Eu tenho esses resquícios ainda de preconceito em mim, que é, por exemplo, não ter um cabelo curto pelo fato de ficar mais masculina, pelo meu estilo. Eu já tenho o estilo assim e aí eu pensei "com o cabelo curto eu vou ficar mais ainda" sabe? Pelo que, por tudo que eu já escutei e eu sei que isso é muito errado, sabe? Porque isso me priva, tipo me deixa privada de muita coisa que eu quero fazer, mas eu também tenho essa necessidade ainda aparecer um pouco mais feminina.”(Juno, 2I anos)

De acordo com Soares (2016) "na perspectiva heteronormativa, é mais aceitável que as lésbicas sejam femininas, aliás, super femininas, para demonstrar que o sexo não se descolou do gênero a despeito que seja lésbica" (p.18). Assim sendo, entende-se que há uma punição social maior para a lésbica que não exerce feminilidade, uma vez que esta "traz o castigo pela ruptura com o heterossexismo e pela dose de resistência ao androcentrismo, destituindo o homem do lugar de referente, como proprietário do masculino" (SOARES, 20I6, p.I8). Consequentemente, como mostra o dossiê sobre lesbocídio no Brasil realizado de 2014 a 2017, as mulheres lésbicas "nãofemininas" são a maioria em números de assassinato no país (DIAS; PERES; SOARES, 2018, p.82). 


\section{Considerações finais}

Em suma, percebe-se que até a adolescência, os processos de descobrimento e auto-aceitação das autoras são parecidos. A maior semelhança entre os relatos está, por sua vez, na infância. Isto é, uma infância marcada por brincadeiras tidas como "de menino" (SOARES, 20I6, p. 173) e apelidos pejorativos. Já durante a adolescência, aquelas de famílias mais religiosas, como no caso de Antonella e Juno, demonstraram uma relutância maior em se aceitar como mulheres lésbicas, devido a um mal-estar religioso com um toque de heterossexualidade compulsória.

$\mathrm{Na}$ infância, a "masculinidade" presente na expressão de gênero das interlocutoras parece não ter o mesmo peso durante a adolescência e a vida adulta, uma vez que nestes últimos, as entrevistadas buscaram performar feminilidade para que não se "pareçam com homens", como um mecanismo de defesa contra o preconceito.

Entretanto, é importante compreender que "não existe uma única feminilidade ou uma única masculinidade com a qual se identificar, e sim, ao contrário" (LACOMBE, 2013). Logo, é necessário compreender a lésbica butch, nacionalmente conhecida como "bofe, maria-homem, macho-fêmea ou caminhoneira" (SOARES, 20I6. p.I6o), não como a reprodução de uma ordem heterossexual, como quem busca imitar o homem hétero, mas como um deslocamento e ressignificação das expressões de gênero (BUTLER, 2003). Um deslocamento doloroso, mas necessário para uma desnaturalização do binarismo sexual e de gênero.

\section{Referências}

BRITTEN, Nicky. Entrevistas qualitativas. In: MAYS, Nicholas; POPE, Catherine (Org.). Pesquisa Qualitativa na Atenção à Saúde. Editora Artmed, 2009, p.23-3I.

BUTLER, Judith. Problemas de gênero: feminismo e subversão da identidade. Tradução de Renato Aguiar. Rio de Janeiro: Civilização Brasileira, 2003.

CARVALHO, Gabriel Zamian; REIS, Aparecido Francisco dos Reis, Com_puta_dor - relações BDSM mediadas digitalmente em Campo Grande/MS. Ártemis, v 2I, n I, 2016. 
DIAS, Maria Clara; PERES, Milene Cristina Carneiro; SOARES, Suane Felippe. Dossiê sobre o lesbocídio no Brasil de 2014 até 2017. Rio de Janeiro: Editora Livros Ilimitados, 2018.

FOUCAULT, Michel. História da sexualidade I: A Vontade do saber. Rio de Janeiro: Graal, 1988.

GEERTZ, Clifford. O dilema do antropólogo entre o "estar lá" e o "estar aqui".

Tradução de Fraya Frehse. Cadernos de Campo, V. 7, N. 7, pp. 205-235, 1998.

GOMES, A. M., REIS, A. F.; KURASHIGE, K. D. A violência e o preconceito: As formas da agressão contra a população LGBT em Mato Grosso do Sul. Caderno Espaço Feminino, v 26, n 2, Jul/Dez. 2013.

LACOMBE, Andrea. Ler[se] nas entrelinhas. Sociabilidade e subjetividades entendidas, lésbicas e afins. 2010. 205f. Tese (Doutorado) - Programa de Pós Graduação em

Antropologia Social, Museu Nacional - Universidade do Rio de Janeiro, Rio de Janeiro, 2010.

LACOMBE, Andrea. De entendidas à sapatonas: socializações lésbicas e masculinidades em um bar do Rio de Janeiro. Cadernos Pagu, n. 28, p.207-225, jan-jun. 2007.

LACOMBE, Andrea. Sobre saias, calças e bonés: expressão de gênero, geração e sedução entre mulheres que "gostam de mulher". Antropolítica, n.34, p. 53-68, r., 2013.

PARAÍSO, Malucy Alves; SILVA, João Paulo de Lorena. Bagunçando as normas de gênero: crianças transviadas e a invenção de outros possíveis no currículo escolar. In:

Seminário Brasileiro de Estudos Culturais e Educação/Seminário Internacional de Estudos Culturais e Educação. 7./4. 2017, Canoas, Rio Grande do Sul: Universidade Luterana do Brasil, Programa de Pós Graduação em Educação ULBRA, 2017, p. 1-13. Disponível em:

<http://www.2017.sbece.com.br/resources/anais/7/I495486395_ARQUIVO_Baguncandoas normasdegenero_SBECE_TextoCompleto.pdf> Acesso em: o7 ago. de 2020.

POMBO, Mariana Ferreira. Desconstruindo e subvertendo o binarismo sexual e de gênero. Revista Periódicus, Salvador, n. 7, v. I, p. 388-404, maio-out. 2017.

REIS, Aparecido Francisco dos. O processo de construção da identidade de gênero e transexualidade: Narrativas, trânsitos e diferenças. Interfaces da Educação, v ıo, n 28, 2019.

REIS, Aparecido Francisco dos; Carlos Eduardo Reis da. Erótica dissidente: A violência e a (re)invenção do corpo e do gênero entres as travestis. Brazilian Journal of Development. Curitiba, v. 6, n. 7, jul. 2020. 
RICH, Adrienne. Heterossexualidade compulsória e existência lésbica. Bagoas - Estudos gays: gêneros e sexualidades, v. 4, n. 05, 27 nov. 2012.

SCOTT, Joan. Gênero: uma categoria útil de análise histórica. Educação e Realidade, Porto Alegre, v20, n.2, p.7I-99, jul./dez, 1995.

SOARES, Gilberta Santos. Sapatos tem sexo? Metáforas de gênero em lésbicas de baixa renda, negras, no nordeste do Brasil. 2016. 28of. Tese (Doutorado) - Programa de Pós Graduação em Estudos Interdisciplinares sobre Mulheres, Gênero e Feminismos do Núcleo de Estudos da Mulher - PPGNEIM, Universidade Federal da Bahia, 2014.

SWAIN, Tânia Navarro. O que é lesbianismo. São Paulo: Editora Brasiliense, 2000. 